\title{
Pertumbuhan dan Distribusi Akar Tanaman Muda Beberapa Genotipe Unggul Jarak Pagar (Jatropha curcas L.)
}

\section{Root Growth and Distribution on The Young Plant of Jatropha curcas L. Superior Genotypes}

\author{
IGM Arya Parwata ${ }^{1}$, Bambang Budi Santoso ${ }^{1}$, IN Soemeinaboedhy ${ }^{1,2}$ \\ ${ }^{1}$ Pusat Studi dan Pengembangan Pertanian Energi (Energy Crops Centre), Fakultas Pertanian, \\ Universitas Mataram, INDONESIA. Tel. +62-0370 621435, Fax. +62-0370 640189 \\ ${ }^{2}$ Jurusan Ilmu Tanah Fakultas Pertanian, Universitas Mataram, INDONESIA \\ *arya.parwata@unram.ac.id
}

Manuscript received: 09-10-2017. Accepted:13-12-2017

\begin{abstract}
ABSTRAK
Perbedaan potensi genetik berpengaruh pada kedalaman perakaran, dan jarak pagar mengubah pola tumbuhnya dalam merespon kondisi lingkungan sehingga tanaman dapat tumbuh dan bertahan pada berbagai kondisi dan jenis tanah, maka pemilihan genotype atau varietas yang akan dikembangkan pada suatu kawasan tertentu perlu menjadi pertimbangan. Penelitian ini bertujuan untuk mengetahuai pertumbuhan perakaran tanaman muda beberapa genotipe unggul jarak pagar. Pembibitan secara langsung pada polibag berisi media tanah-kompos $(1: 1 \mathrm{v} / \mathrm{v})$ di bawah naungan paranet selama 2 bulan, sebanyak 3 ulangan (masing-masing 25 bibit). Sejumlah 20 bibit berumur 2 bulan ditanam di lapangan berjarak tanam $1.5 \times 2.0 \mathrm{~m}$ diatur secara grid systim. Pengamatan akar dilakukan dengan cara membongkar media tumbuh. Hasil penelitian menunjukkan bahwa selama periode 6 bulan, tidak ada perbedaan pertumbuhan akar antar genotype.Akar tunggang tumbuh geotropik dengan empat akar lateral yang tumbuh horizontal dan terkonsentrasi pada pangkal akar tunggang, sehingga membentuk sistim perakaran dangkal. Pertumbuhan (panjang dan diameter) akar tunggang tampak lebih mendominasi keempat akar lateral.
\end{abstract}

Kata Kunci: arsitektur akar, biomassa akar, distribusi akar, geotropic

\begin{abstract}
Since there are differences in genetic potential effect on rooting depth, and also Jatropha curcas change the pattern of growth in response to environmental conditions so that the plants can grow and survive in various conditions and soil types, then the selection of genotypes or varieties to be developed in a particular area should be considered. This study aims to know the growth of young plant root of superior genotypes of Jatropha curcas. Seeding directly in polybags plastic containing medium mixtures of soil-compost (1: $1 \mathrm{v} / \mathrm{v})$ under shade net for 2 months, as many as 3 replicates (each 25 seeds). Some 20 seedlings of 2 months old were field planting with $1.5 \mathrm{~m}$ x $2.0 \mathrm{~m}$ spacing arranged in a grid system. Root growth observations were done by dig growing medium. The results showed that during the period of 6 months, there were no differences of root growth between genotype. Tap-root grows geotropic with four lateral roots that grow horizontally and concentrated at
\end{abstract}


the base of the taproot, thus forming a shallow rooting system. Root growth, length and diameter, of tap-root appeared to be greater to four lateral roots.

Keywords: architectural roots, root biomass, root distribution, geotropic

\section{PENDAHULUAN}

Tanaman jarak pagar (Jatropha curcas Linn.) selain sebagai sumber bahan bakar alternatif, juga dikenal sebagai tanaman yang memiliki kemampuan adaptasi tinggi dan dapat digunakan sebagai tanaman konservatif tanah dan akhirnya dapat memperbaiki lingkungan. Tanaman ini berpotensi untuk dikembangkan pada daerah marginal atau lahan kering dan mampu memperbaiki lahan terdegradasi dan penghijauan hutan yang rusak (Liu et al. 2012). Namun demikian, seberapa jauh daya adaptasi tanaman tersebut belum banyak dipublikasikan secara mendalam.

Sebagai tanaman tahunan yang akan dimanfaatkan kegunaannya sebagai alat konservasi lingkungan, harus memiliki persyaratan daya tumbuh yang baik. Daya tumbuh yang baik, dipengaruhi oleh salah satunya adalah faktor akar. Diketahui bahwa pertumbuhan tajuk tanaman berkorelasi dengan pertumbuhan akar. Kualitas pertumbuhan tanaman tahunan diawali dari kondisi pertumbuhan sejak semai.

Pertumbuhan bibit selanjutnya dan tanaman muda hingga tanaman mencapai dewasa ditentukan oleh sistim perakarannya. Arsitektur atau sistim perakaran mendukung percepatan pertumbuhan tanaman dari sejak tahap awal pertumbuhan melalui kemampuannya mengekstrak ketersediaan air pada lapisan tanah dangkal (atas) yang mudah hilang karena evaporasi (Johansen et al. 1997) dan juga kemampuan mengekstrak air dari lapisan tanah dalam akan mendukung kemampuan tanaman beradaptasi (Kashiwagi et al. 2006).

Akar tanaman merupakan bagian terpenting dalam beradaptasi dengan lingkungannya sekaligus sebagai alat mekanik dalam mencegah terjadinya longsor (Ziemer, 1981) melalui mekanisme cengkraman tanah di lapisan permukaan (kedalaman 0-5 cm) oleh akar yang menyebar horizontal; dan menopong tegaknya batang sehingga pohon tidak mudah tumbang oleh dorongan massa tanah, sehingga dapat dikatakan bahwa kemampuan akar pepohonan dalam meningkatkan kekuatan geser tanah ditaksir dengan mengukur kerapatan panjang akar. Demikian pula halnya dengan kemampuan tanaman dapat bertahan hidup pada lahan kering (marginal) dikarenakan arsitektur perakaran yang dibentuk, seperti kedalaman perakaran dan penyebaran akar-akar lateral beserta bulu-bulu akar yang tumbuh dan berkembang lebih kecil (Kashiwagi et al. 2006).

Faktor genetik yang mempengaruhi daya adaptasi tanaman jarak pagar setelah di lahan pertanaman adalah arsitektur atau sistim perakarannya. Akar kecambah berasal dari radikula yang terus tumbuh geotropis menghasilkan satu buah akar tunjang dengan empat buah akar lateral (Santoso, 2010; Santoso, 2009). Oleh Krishnamurthy et al. (2012), dikatakan bahwa sistim perkaranan tanaman jarak pagar termasuk dangkal, terdistribusi menyebar utamanya di lapisan tanah bagian atas. Oleh karena itu, dengan adanya pola perakaran tersebut menyebabkan sistem perakaran jarak pagar dapat mempertahankan tanah dari erosi air maupun angin (Reubenset al. 2011), namun akan mudah rebah.

Walaupun telah diketahui betapa pentingnya akar bagi pertumbuhan tanaman, namun program pemuliaan dalam skala luas terkait arsitektur perakaran sebagai komponen toleransi kekeringan belum banyak dikaji secara mendalam (Kamoshita et al. 2002). Sejak adanya 
perbedaan potensial genetik dari jenis tanaman terhadap tingkat kedalaman perakarannya pada lingkungan yang sama (Day et al. 2010; Pregitzer et al. 2008), dan bahwa jarak pagar mengubah pola tumbuhnya dalam merespon kondisi lingkungan sub-optimal sehingga tanaman dapat tumbuh dan bertahan pada berbagai kondisi dan jenis tanah (Valdes-Rodriques et al. 2013), maka pemilihan jenis atau spesies atau varietas tanaman yang akan dikembangkan pada suatu kawasan atau areal tertentu perlu menjadi pertimbangan. Demikian pula halnya dengan pemilihan jenis-jenis unggul tanaman jarak pagar yang telah ada perlu dilakukan untuk suatu daerah pengembangan tertentu. Penelitian ini bertujuan untuk mengetahuai pertumbuhan perakaran bibit dan tanaman muda beberapa genotipe unggul jarak pagar.

\section{BAHAN DAN METODE}

\section{Bahan Tanaman dan Lokasi Percobaan}

Tanaman jarak pagar yang digunakan berupa genotype unggul lokal LB dan IP-2 NTB, serta unggul nasional IP-3A, IP-3M, dan IP-3P. Bibit dipersiapkan dengan teknik pembibitan langsung (penanaman biji pada polibag). Pembibitan dan penanaman dilakukan di Dusun Amor-Amor, Kecamatan Kayangan, Kabupaten Lombok Utara dengan lokasi $8^{\mathrm{O}} 16^{\prime} 15.02$ ''S $116^{\mathrm{O}} 17^{\prime} 34.02$ '' $\mathrm{T}$ pada $75-100 \mathrm{~m}$ dpl. Lahan pertanaman berupa lahan kering bertipe tanah Entisol geluh pasiran dengan komposisi $69 \%$ pasir, 25\% debu, 5\% geluh/liat, $1,8 \%$ karbon organik, $0.2 \%$ total $\mathrm{N}$, pH 5.9-6.3, dan kapasitas tukar kation 7.2-10.4 cmol. $\mathrm{kg}^{-1}$.

\section{Pembibitan dan Percobaan}

Kelima lot benih direndam selama satu malam sebelum ditanam, dan kemudian ditanam pada polibag hitam berukuran $15 \mathrm{~cm}$ diameter x $25 \mathrm{~cm}$ tinggi berisikan media tanah dicampur kompos $(1: 1 \mathrm{v} / \mathrm{v})$. Bibit dipelihara di bawah naungan paranet dan dipelihara hingga umur 2 bulan. Masing-masing lot terdiri dari 3 ulangan dan tiap ulangan menggunakan 25 benih. Sejumlah masing-masing 20 bibit berumur 2 bulan dipilih dan kemudian ditanam di lapangan, pada bulan April 2016, berjarak tanam $1.5 \mathrm{~m}$ x $2.0 \mathrm{~m}$ yang diatur secara grid sistim (baris masing-masing genotype).

\section{Perawatan Pertanaman}

Pada saat tanam, masing-masing lobang tanam diberikan $1 \mathrm{~kg}$ pupuk kandang sapi dan 5 g Furadan. Pemberian pupuk Urea dengan dosis $600 \mathrm{~kg} \cdot \mathrm{ha}^{-1}$. diberikan pada saat tanam bersamaan dengan pemberian Ponska, sebanyak 350 kg.ha ${ }^{-1}$. Pemberian pupuk Ponska berikutnya dilakukan pada saat tanaman telah berumur 2 bulan setelah penanaman dengan dosis $700 \mathrm{~kg} \cdot \mathrm{ha}^{-1}$ dengan cara tugal di kiri/kanan tanaman dengan jarak sekitar $10 \mathrm{~cm}$ dari tanaman. Pengairan dilakukan 2 minggu sekali sampai tanaman berumur 2 bulan setelah penanaman, dan kemudian satu kali setiap satu bulan hingga tanaman berumur 6 bulan setelah penanaman.

\section{Pengamatan dan Analisis Data}

Pengamatan dilakukan terhadap beberapa tolok ukur pertumbuhan bibit yaitu jumlah akar lateral, panjang akar lateral, panjang akar tunggang, diameter akar lateral, diameter akar tunggang, bobot biomassa akar terhadap bibit berumur 1 bulan dan2 bulan. Pengamatan juga 
dilakukan terhadap tanaman berumur 4 bulan dan 6 bulan yang tumbuh di lapangan. Pengamatan akar dilakukan terhadap 3 tanaman (3 ulangan) masing-masing genotipe untuk tiap umur pengamatan. Data dianalisis dengan Anova 5\% dan uji lanjut HSD 5\% dengan menggunakan aplikasi Minitab-14.

\section{HASIL DAN PEMBAHASAN}

Kelima genotype unggul jarak pagar yang tumbuh dan berkembang pada tipe tanah Entisol geluh pasiran tidak menunjukkan perbedaan secara nyata pada pertumbuhan akar yang meliputi jumlah akar lateral (Tabel 1), panjang akar lateral (Tabel 2), panjang akar tunggang (Tabel 3), diameter akar lateral (Tabel 4), diameter akar tunggang (Tabel 5), distribusi akar lateral (Tabel 6), dan bobot kering akar (Tabel 7), khususnya pada periode 1-6 bulan pertumbuhannya. Dikatakan oleh Hodge et al. (2009), bahwa arsitektur sistim perakaran sangat bervariasi di antara spesies tanaman yang berbeda, tetapi dalam satu spesies arsitektur akar fleksibel dan berubah bergantung pada kondisi tanah. Pola susunan (arsitektur) akar tanaman jarak pagar dikatakan oleh Valdes-Rodrigues et al. (2013) dipengaruhi oleh genetik tanaman dibandingkan dipengaruhi oleh lingkungan, terutama tekstur tanah. Kelima genotype unggul jarak pagar yang diuji dalam penelitian ini merupakan populasi terperbaiki (Improved Population) melalui seleksi massa dari populasi liar yang ada hubungan kekerabatannya satu sama lainnya, terutama daerah asal (provenan). Ditambahkan oleh Ginwal et al. (2004) bahwa penyerbukan silang pada jarak pagar hampir tidak mengubah secara berarti karakteristik morfologi.

Tabel 1. Jumlah akar lateral beberapa genotype jarak pagar pada berbagai umur

\begin{tabular}{lcccc}
\hline \multirow{2}{*}{ Genotipe } & \multicolumn{5}{c}{ Jumlah akar lateral } \\
\cline { 2 - 5 } & 1 bulan & 2 bulan & 4 bulan & 6 bulan \\
\hline IP-3 A & 4 & 4 & 4,2 & 5,7 \\
IP-3 M & 4 & 4 & 4,6 & 5,8 \\
IP-3 P & 4 & 4 & 4,2 & 5,5 \\
IP-2 NTB & 4 & 4 & 4,2 & 5,7 \\
LB & 4 & 4 & 4,1 & 6,3 \\
\hline \multicolumn{1}{c}{ HSD 5\% } & ns & ns & ns & ns \\
\hline
\end{tabular}

Keterangan: $n s$ = non significantly different (berbeda tidak nyata)

Tabel 2. Rerata panjang akar lateral beberapa genotype jarak pagar pada berbagai umur

\begin{tabular}{lcccc}
\hline \multirow{2}{*}{ Genotipe } & \multicolumn{4}{c}{ Panjang akar lateral $(\mathbf{c m})$} \\
\cline { 2 - 5 } & 1 bulan & 2 bulan & 4 bulan & 6 bulan \\
\hline IP-3 A & 10.9 & 15.7 & 20.5 & 26.5 \\
IP-3 M & 10.8 & 15.8 & 21.3 & 26.8 \\
IP-3 P & 10.5 & 16.3 & 21.1 & 26.1 \\
IP-2 NTB & 10.6 & 15.6 & 19.2 & 25.5 \\
LB & 11.3 & 16.3 & 20.1 & 27.5 \\
\hline \multicolumn{1}{c}{ HSD 5\% } & ns & ns & ns & ns \\
\hline
\end{tabular}

Keterangan: $\mathrm{ns}=$ non significantly different (berbeda tidak nyata)

Sehubungan dengan tidak adanya beda nyata pertumbuhan dan perkembangan akar kelima genotype unggul yang diuji dalam penelitian ini, dan berdasarkan pada data Tabel 1 
hingga Tabel 7, maka dapat diuraikan bahasan sebagai berikut ini. Arsitektur perakaran kelima genotype unggul jarak pagar yang diuji dari sejak awal perkembangannya hingga tanaman muda berumur 6 bulan menunjukkan arsitektur yang unik, akar tunggang yang tumbuh geotropik dengan empat akar lateral yang tumbuh horizontal. Distribusi akar lateral terkonsentrasi pada pangkal akar tunggang, sehingga sistim perakarannya termasuk dangkal. Hal ini sesuai dengan hasil penelitian Krishnamurthy et al. (2012), bahwa sistim perkaranan tanaman jarak pagar termasuk dangkal, dikarenakan terdistribusi menyebar utamanya di lapisan tanah bagian atas. Oleh $\mathrm{Ci}$ dan Yang (2010), posisi akar lateral yang tumbuh dekat dengan permukaan tanah merupakan sifat tanaman yang beradaptasi pada daerah beriklim kering.

Tabel 3. Panjang akar tunggang beberapa genotype jarak pagar pada berbagai umur

\begin{tabular}{lcccc}
\hline \multirow{2}{*}{ Genotipe } & \multicolumn{4}{c}{ Panjang akar tunggang $(\mathbf{c m})$} \\
\cline { 2 - 5 } & 1 bulan & 2 bulan & 4 bulan & 6 bulan \\
\hline IP-3 A & 10.6 & 14.9 & 19.5 & 25.9 \\
IP-3 M & 10.1 & 14.7 & 20.1 & 25.1 \\
IP-3 P & 10.3 & 15.6 & 21.5 & 25.7 \\
IP-2 NTB & 10.5 & 14.9 & 18.6 & 26.7 \\
LB & 10.9 & 15.7 & 19.1 & 26.1 \\
\hline \multicolumn{1}{c}{ HSD 5\% } & ns & ns & ns & ns \\
\hline
\end{tabular}

Keterangan: $\mathrm{ns}=$ non significantly different (berbeda tidak nyata)

Tabel 4. Rerata diameter akar lateral beberapa genotype jarak pagar pada berbagai umur

\begin{tabular}{|c|c|c|c|c|c|c|}
\hline \multirow{3}{*}{ Genotipe } & \multicolumn{6}{|c|}{ Diameter akar lateral (cm) } \\
\hline & \multicolumn{2}{|c|}{2 bulan } & \multicolumn{2}{|c|}{4 bulan } & \multicolumn{2}{|c|}{6 bulan } \\
\hline & $\mathbf{U}$ & $\mathbf{P}$ & $\mathbf{U}$ & $\mathbf{P}$ & $\mathbf{U}$ & $\mathbf{P}$ \\
\hline IP-3 A & 0.20 & 0.45 & 0.29 & 0.62 & 0.40 & 1.20 \\
\hline IP-3 M & 0.15 & 0.38 & 0.27 & 0.58 & 0.35 & 1.02 \\
\hline IP-3 P & 0.15 & 0.36 & 0.25 & 0.55 & 0.35 & 0.95 \\
\hline IP-2 NTB & 0.22 & 0.42 & 0.31 & 0.60 & 0.40 & 1.22 \\
\hline LB & 0.20 & 0.40 & 0.33 & 0.58 & 0.38 & 1.20 \\
\hline HSD 5\% & $\mathrm{ns}$ & ns & $\mathrm{ns}$ & ns & $\mathrm{ns}$ & $\mathrm{ns}$ \\
\hline
\end{tabular}

Keterangan: $\mathrm{U}=$ ujung, $\mathrm{P}=$ pangkal, $\mathrm{ns}=$ non significantly different (berbeda tidak nyata)

Tabel 5. Diameter akar tunggang beberapa genotype jarak pagar pada berbagai umur

\begin{tabular}{lcccccc}
\hline \multirow{2}{*}{ Genotipe } & \multicolumn{6}{c}{ Diameter akar tunggang (cm) } \\
\cline { 2 - 7 } & $\mathbf{2}$ 2 bulan & $\mathbf{P}$ & $\mathbf{U}$ & $\mathbf{P}$ & $\mathbf{U}$ & $\mathbf{P}$ \\
\cline { 2 - 7 } & 0.30 & 0.52 & 0.60 & 1.28 & 0.44 & 1.23 \\
IP-3 A & 0.28 & 0.45 & 0.52 & 1.08 & 0.38 & 1.05 \\
IP-3 M & 0.25 & 0.42 & 0.48 & 1.02 & 0.36 & 0.98 \\
IP-3 P & 0.32 & 0.50 & 0.62 & 1.30 & 0.45 & 1.25 \\
IP-2 NTB & 0.30 & 0.55 & 0.58 & 1.32 & 0.41 & 1.22 \\
LB & ns & ns & ns & ns & ns & ns \\
\hline \multicolumn{1}{c}{ HSD 5\% } &
\end{tabular}

Keterangan: $\mathrm{U}=$ ujung, $\mathrm{P}=$ pangkal, $\mathrm{ns}=$ non significantly different (berbeda tidak nyata) 
Pertumbuhan akar (Tabel 4 dan Tabel 5) terutama akar tunggang dalam hal ini diameter akar lebih mendominasi daripada pertumbuhan akar lateral hingga umur 4 bulan. Setelah itu, pada umur 6 bulan, nampak bahwa pertumbuhan akar lateral terlihat mulai pesat dibandingkan akar tunggang. Terbentuk pula beberapa akar lateral di sepanjang akar tunggung terutama dekat dengan pangkal akar tunggal dimana disana telah tumbuh akar lateral dari sejak perkecambahan. Tabel 6 memaparkan distribusi perakaran tanaman jarak pagar genotype unggul. Penambahan jumlah akar lateral yang terbentuk dimulai pada saat tanaman berumur 4 bulan dan tumbuh-berkembangnya akar-akar tersebut berposisi di bagian bawah empat buah akar-akar leteral yang pertama kali terbentuk saat perkecambahan biji.

Seiring dengan pertambahan ukur tanaman, pertumbuhan akar tanaman jarka pagar terus bertambah pula (Tabel 7). Pertumbuhan yang dimanifestasikan dalam variable bobot akar total merupakan keseluruhan dari sistim perakaran yang terbentuk, yaitu terdiri atas akar tunggang dan akar lateral beserta bulu-bulu akarnya.

Arsitektur akar bibit jarak pagar umur 1-2 bulan yang tumbuh pada tanah berpasir dilaporkan oleh Reubens at al. (2011) didominasi oleh akar tunggang hingga 50\% biomassa total akar.Ditambahkan oleh Valdes-Rodrigues et al. (2013) bahwa terdapat peningkatan biomassa dan ukuran akar tunggang seiring dengan penambahan umur dibandingkan akar lateral. Hal ini dikarenakan perpanjangan akar tunggang dan juga bersamaan dengan pertumbuhan dan perkembangan akar lateral yang tetap dangkal, dan sekaligus mengindikasikan bahwa bibit jarak pagar terus mencari sumber makanan ke tanah yang ada dipermukaan dan juga di bagian dalam tanah.

Tabel 6. Distribusi jumlah akar lateral beberapa genotype jarak pagar pada berbagai umur

\begin{tabular}{|c|c|c|c|c|c|c|c|c|c|c|c|c|}
\hline \multirow{3}{*}{ Genotipe } & \multicolumn{12}{|c|}{ Distribusi jumlah akar lateral } \\
\hline & \multicolumn{3}{|c|}{1 bulan } & \multicolumn{3}{|c|}{2 bulan } & \multicolumn{3}{|c|}{4 bulan } & \multicolumn{3}{|c|}{6 bulan } \\
\hline & $\mathbf{A}$ & $\mathbf{T}$ & B & $\mathbf{A}$ & $\mathbf{T}$ & B & $\mathbf{A}$ & $\mathbf{T}$ & B & A & $\mathbf{T}$ & B \\
\hline IP-3 A & 4 & - & - & 4 & - & - & 4.1 & 1.2 & - & 4.1 & 1.3 & 0.7 \\
\hline IP-3 M & 4 & - & - & 4 & - & - & 4.0 & 1.5 & - & 4.0 & 1.5 & - \\
\hline IP-3 P & 4 & - & - & 4 & - & - & 4.0 & 1.0 & - & 4.0 & 1.1 & - \\
\hline IP-2 NTB & 4 & - & - & 4 & - & - & 4.2 & 1.3 & - & 4.3 & 1.4 & 1.1 \\
\hline LB & 4 & - & - & 4 & - & - & 4.1 & 1.2 & - & 4.1 & 1.5 & 0.9 \\
\hline
\end{tabular}

Keterangan : Bagian atas (A), tengah (T), dan bawah (B) dari akar tunggang

Tabel 7. Bobot kering total akar beberapa genotype jarak pagar pada berbagai umur

\begin{tabular}{lcccc}
\hline \multirow{2}{*}{ Genotipe } & \multicolumn{4}{c}{ Bobot kering akar $(\mathbf{g})$} \\
\cline { 2 - 5 } & 1 bulan & 2 bulan & 4 bulan & 6 bulan \\
\hline IP-3 A & 0.42 & 0.64 & 1.91 & 5.71 \\
IP-3 M & 0.38 & 0.62 & 1.83 & 5.45 \\
IP-3 P & 0.39 & 0.58 & 1.72 & 5.13 \\
IP-2 NTB & 0.57 & 0.96 & 2.36 & 6.22 \\
LB & 0.51 & 0.81 & 2.15 & 5.93 \\
\hline \multicolumn{1}{c}{ HSD 5\% } & ns & ns & ns & ns \\
\hline
\end{tabular}

Keterangan: $\mathrm{ns}=$ non significantly different (berbeda tidak nyata) 
Arsitektur akar jarak pagar hingga tanaman berumur 6 bulan dan dengan adanya satu akar tunggang dan empat akar lateral yang memiliki derajat pertumbuhan sama serta terdistribusi merata ke seluruh arah mata angin serta adanya akar lateral yang tumbuh berkembang di akar tunggang, maka struktur bercabangan akar mengikuti pola berbentuk V, yang oleh Valdes-Rodrigues et al. (2013) dikatakan struktur percabangan tulang ikan (herring-bone). Oleh karena struktur yang demikian itu, tanaman jarak pagar memiliki efisiensi yang tinggi dalam mengeksplorasi tanah (Danjon dan Reubens, 2008) dan juga menyebabkan jarak pagar dapat beradaptasi pada tanah kering dan miskin unsur hara (Kolke et al., 2003).

Gambar 1. mengilustrasikan pertumbuhan dan perkembangan serta distribusi akar tanaman muda (1 hingga 6 bulan) jarak pagar. Akar kecambah berasal dari radikula yang terus tumbuh geotropis menghasilkan satu buah akar tunggang dengan diikuti empat buah akar lateral yang tumbuh horisontal. Empat akar lateral yang tumbuh dan berkembang pada kedalaman yang relatif sama pula $(2.5-3.0 \mathrm{~cm})$ sepanjang akar tunggang membentuk sudut inklinasi yang sama pula sehingga dapat dikatakan membentuk pola sebaran yang simestris. Akar lateral kemudian mulai tumbuh condong ke arah vertikal (geotropis) setelah memasuki umur 4 bulan. Kenampakan simetris pula mulai tampak ada perubahan. Simetris pola pertumbuhan akar lateral tidak saja tampak pada sudut/inklinasi arah tumbuh tetapi juga pada distribusi penimbunan biomassa. Penimbunan biomassa pada masing-masing akar lateral tampak simetris satu sama lainnya. Hal ini tampak pada berat dan ukuran diameter dari ke empat akar lateral tersebut sama. Akan tetapi, akar tunggal pada umur 6 bulan nampak membesar dibandingkan ke empat akar lateral yang tumbuh dan berkembangnya relatif bersamaan waktu di saat fase kecambah.

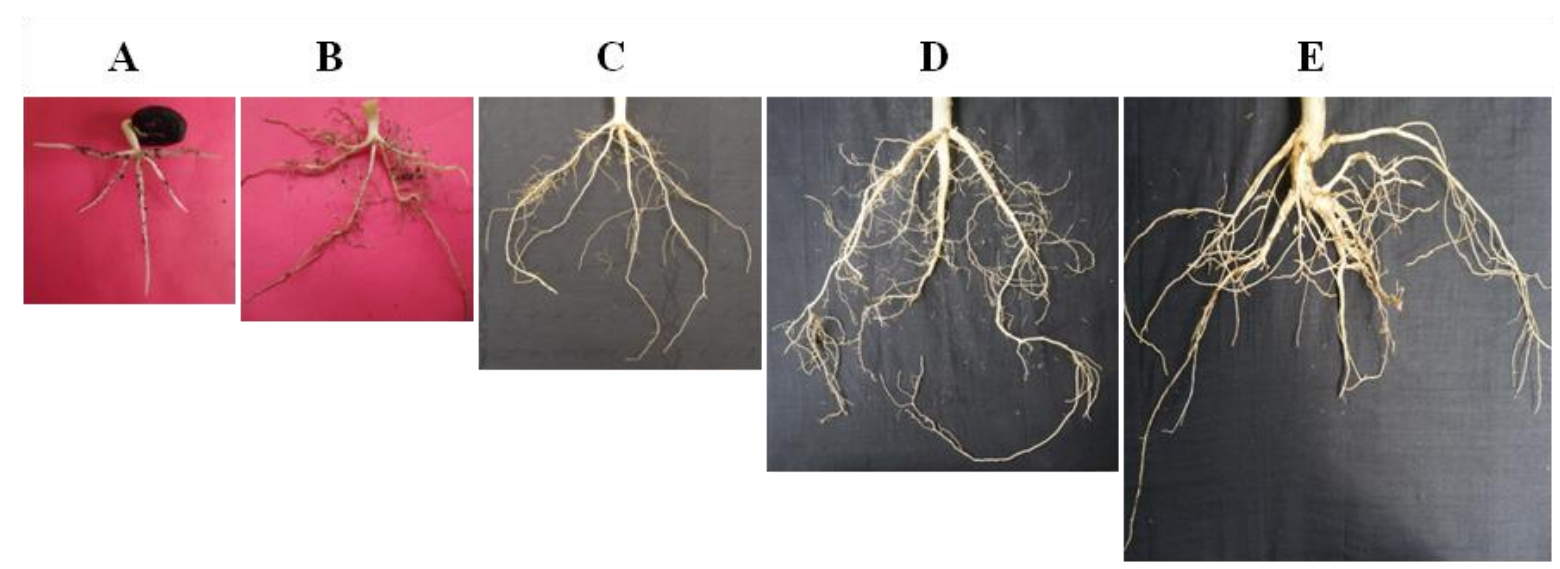

Gambar 3. Arsitektur dan distribusi akar tanaman jarak pagar pada berbagai tingkat umur. A. Perakaran pada kecambah umur 3 hari, B. Perakaran tanaman umur 1 bulan setelah tanam biji, C. Perakaran tanaman umur 2 bulan setelah tanam biji, D. Perakaran tanaman umur 4 bulan setelah tanam biji, E. Perakaran tanaman umur 6 bulan setelah tanam biji

Bahwasannya struktur sistim perakaran tunggang yang tebal dengan empat akar lateral yang tumbuh tegak lurus terhadap akar tunggang, maka sistim perakaran ini dapat 
mendukung kuatnya tanaman berdiri tegak. Struktur sistim perakaran seperti ini juga akan menambah stabilnya agregat tanah yang dilalui oleh akar-akar tersebut (yang berada dalam jeluk perakaran). Hal ini sejalan dengan Krishnamurthy et al. (2012) dan ziemer (1981).

\section{KESIMPULAN}

Secara umum dapat dikatakan bahwa pertumbuhan dan distribudi akar tanaman muda beberapa genotipe unggul jarak pagar (Jatropha curcas L.) selama periode 6 bulan, tidak menunjukkan perbedaan nyata antar genotipe. Akar tunggang tumbuh geotropik dengan empat akar lateral yang tumbuh horizontal dan terkonsentrasi pada pangkal akar tunggang, sehingga membentuk sistim perakaran dangkal. Hingga umur 6 bulan, pertumbuhan yang pesat terutama pada ukuran diameter akar tunggal tampak mendominasi.

\section{Ucapan Terima Kasih}

Terima kasih disampaikan kepada Direktorat Riset dan Pengabdian MasyarakatDirektorat Jenderal Penguatan Riset dan Pengembangan Kementerian Riset, Teknologi, dan Pendidikan Tinggi yang telah mendanai penelitian ini melalui Skim Penelitian Unggulan Perguruan Tinggi dengan kontrak nomor 134/SP2H/LT/DRPM/III/2016, Tanggal 10 Maret 2016

\section{DAFTAR PUSTAKA}

Day, SD., PE. Wiseman, SB. Dickison, JR. Harris. 2010. Contemporary concepts of root system architecture of urban trees. Arboriculture \& Urban Forestry. 36(4):149-157.

Ginwal, H.S., P.S. Rawat, R.L. Srivastava. 2004. Seed source variation in growth performance and oil yield of Jatropha curcas Linn. in Central India. Silvae Genetica 53, 4: 186-192.

Johansen, C., Singh, DN., Krishnamurthy, L., Saxena, NP., Chauhan, YS., Kumar Rao, JVDK. 1997. Option for alleviating moisture stress in pulse crops. In: Asthana, AN., Masood Ali, (Eds). Recent advances in pulses research. Indian Society of Pulses Research and Development, IIPR, Kanpur, India, pp:425-442.

Kamoshita A, Jingxian Zhang, Siopongco, J., Sarkarung, S., Nguyen, HT., Wade, L.J. 2002. Effect of phenotyping environment on identification of quantitative trait loci for rice morphology under anaerobic conditions. Crop Sci. 42:255-265.

Kashiwagi, J., L. Krishnamurthy, JH. Crouch, R. Serraj. 2006. Variability of root length density and its contributions to seed yield in chickpea (Cicer arietinum L.) under terminal drought stress. Field Crops Research. 95:171-181.

Krishnamurthy, L., M. Zaman-Allah, S. Marimuthu, SP. Wani, AVR Kesava-Rao. 2012. Root growth in Jatropha and its implication for drought adaptation. Biomass and Bioenergy. http://dx.doi.org/10.1016/j.biombioe.2012.01.015.

Liu K., Yang Q., GE. Zhenyang, Liu Xiaogang. 2012. Simulation of Jatropha curcas L. root in respon to water stress based on 3D visualization. Procedia Engineering. 28:403-408.

Pregitzer, KS., JL. DeForest, AJ. Burton, MF. Allen, R.W. Ruess, R.L. Hendrick. 2008. Fine root architecture of nine North American trees. Ecological Monographs. 72(2):293-309.

Reubens, B.; W.M.J. Achten; W.H.Maesetal. 2011. More than biofuel? Jatropha curcas root system symmetry and potential for soil erosion control," J. of Arid Environments.

Vol.75, No.2, 201-205.

Santoso, BB., BS. Purwoko. 2008a. Teknik pembibitan tanaman jarak pagar (Jatropha curcas L.) - Technic of Physic Nut (Jatropha curcas L.) Seedling. CropAgro. 1(2):77-84. 
Santoso, BB., BS. Purwoko. 2008b. Pertumbuhan bibit tanaman jarak pagar (Jatropha curcas L.) pada berbagai kedalamandan posisi tanam benih - Growth of Physic Nut (Jatropha curcas L.) Seedling on several positions and depth of seed sowing.Bul. Agron. 36(1):70-77.

Santoso, B.B. 2009. Karakterisasi Morfo-ekotipe dan kajian beberapa aspek agronomi jarak pagar (Jatropha curcas L.) di Nusa Tenggara Barat. Disertasi Sekolah Pascasarjana IPB, Bogor.

Santoso, B.B. 2010. Tinjauan agronomi dan teknologi budidaya jarak pagar (Jatropha curcas L.). Arga Puji Press, Mataram, Lombok, NTB. 170h.

Valdes-Rodriques, OA; JS. Caplan; O. Sánchez-Sánchez; F. Danjon. 2013. Jatropha curcas L. root structure and growth in diverse soils. The Scientific World Journal, Vol. 2013, Article ID 827295, 9 pages. http://dx.doi.org/10.1155/2013/827295

Ziemer, RR. 1981. Roots and the stability of forested slopes. Erosion and sediment transport in Pasific Rim Steeplands. IAHS Publ no.132. 